Case Report

\title{
Concurrent Rotator Cuff Tear and Axillary Nerve Palsy Associated with Anterior Dislocation of the Shoulder and Large Glenoid Rim Fracture: A "Terrible Tetrad"
}

\author{
Fumiaki Takase, Atsuyuki Inui, Yutaka Mifune, Tomoyuki Muto, \\ Yoshifumi Harada, Takeshi Kokubu, and Masahiro Kurosaka \\ Department of Orthopaedic Surgery, Kobe University Graduate School of Medicine, Kobe 650-0017, Japan \\ Correspondence should be addressed to Fumiaki Takase; gogotea23@msn.com
}

Received 30 April 2014; Accepted 30 May 2014; Published 12 June 2014

Academic Editor: Hiroshi Hatano

Copyright (C) 2014 Fumiaki Takase et al. This is an open access article distributed under the Creative Commons Attribution License, which permits unrestricted use, distribution, and reproduction in any medium, provided the original work is properly cited.

We present a case of concurrent rotator cuff tear and axillary nerve palsy resulting from anterior dislocation of the shoulder and a large glenoid rim fracture-a "terrible tetrad." A 61-year-old woman fell on her right shoulder. Radiographs showed anterior dislocation of the shoulder with a glenoid rim fracture, and an MRI two months after injury revealed a rotator cuff tear. Upon referral to our hospital, physical and electrophysiological examinations revealed axillary nerve palsy. The axillary nerve palsy was incomplete and recovering, and displacement of the glenoid rim fracture was minimal and already united; therefore, we surgically repaired only the rotator cuff tear three months after injury. The patient recovered satisfactorily following the operation. In patients whose axillary nerve palsy is recovering, surgeons should consider operating on rotator cuff tears in an attempt to prevent rotator cuff degeneration.

\section{Introduction}

Gonzalez and Lopez first reported the combination of peripheral nerve injury and rotator cuff tear following anterior dislocation of the shoulder in 1991 [1]. The combination of pathologies was termed the "unhappy triad" of the shoulder in 1994 [2], and the "terrible triad" of the shoulder in 1995 [3]. The incidence of the "terrible triad" was assumed to be 9-18\% of all shoulder dislocations [4]. There has been no reported case of the "terrible triad" with concomitant glenoid rim fracture. We report a unique case of concurrent rotator cuff tear and axillary nerve palsy associated with anterior dislocation of the shoulder and a large glenoid rim fracture"a terrible tetrad" as we defined.

\section{Case Presentation}

A 61-year-old woman fell over a barrier curb while walking and bruised her right shoulder. A local clinic examined the patient and diagnosed her with anterior dislocation of the shoulder with a glenoid rim fracture (Figure 1(a)). The right shoulder had been immobilized with a sling for a month after immediate reduction (Figure 1(b)). However, the active range of motion for the shoulder remained limited. An MRI scan two months after injury revealed rupturing of the supraspinatus tendon. The patient was referred to our hospital for further management. Clinical examination found stiffness in the right shoulder with muscular weakness. Respective ranges for active and passive right shoulder flexion were 30 degrees and 120 degrees. There was sensory disturbance over the lateral aspect of the shoulder. Radiographs and CT scanning revealed a large anteroinferior glenoid rim fracture, a type IA fracture under the Ideberg classification $[5,6]$. The articular surface was displaced by $2.5 \mathrm{~mm}$, and the width of the bony fragment was 30\% of the glenoid length. Upon initial presentation at our hospital, the fracture had already achieved partial union (Figure 2); therefore, we treated the glenoid rim fracture conservatively. An MRI scan showed a large tear approximately $3 \mathrm{~cm}$ long in the supraspinatus tendon, with atrophy and fatty degeneration 


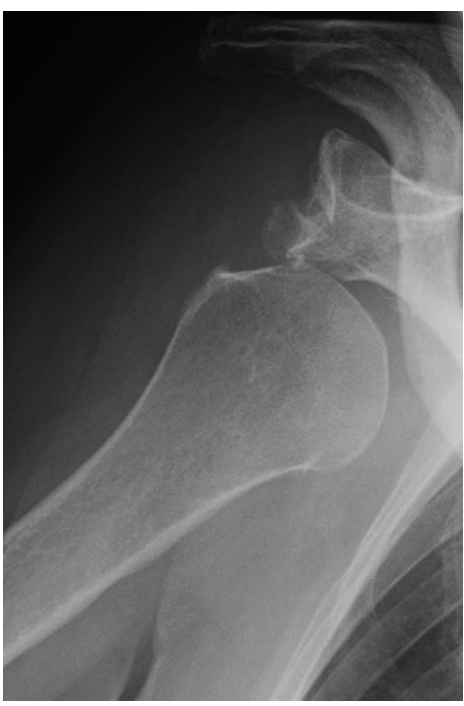

(a)

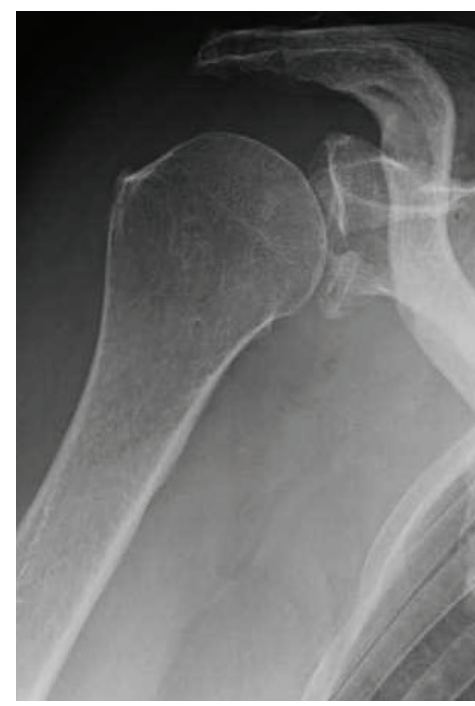

(b)

Figure 1: (a) X-ray imaging at the time of injury. (b) X-ray imaging after reduction of anterior shoulder dislocation.

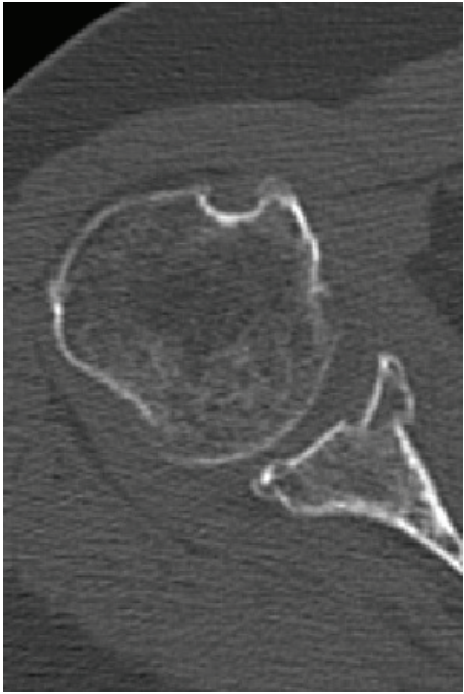

(a)

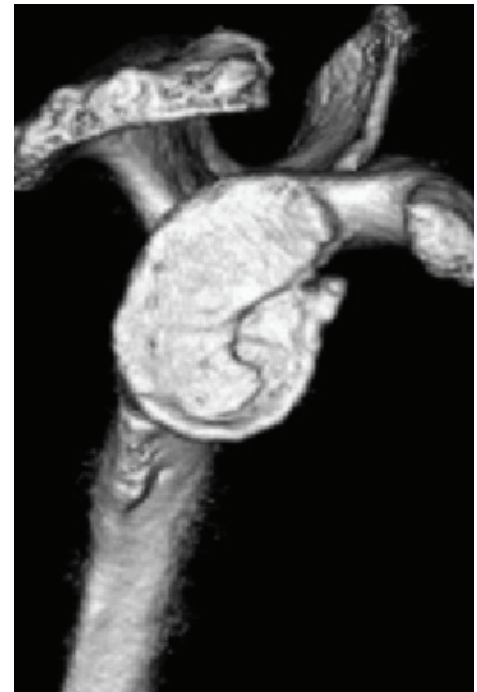

(b)

FIGURE 2: CT imaging upon initial presentation at our hospital. (a) Axial CT imaging showing a large glenoid rim fracture and an articular step-off of $2.5 \mathrm{~mm}$. (b) The width of the bony fragment was 30\% of the glenoid length on the three-dimensional CT.

of the supraspinatus muscle (Figure 3). Electromyography and nerve conduction studies showed an incomplete lesion of the axillary nerve; therefore, we diagnosed axillary nerve palsy in addition to glenoid rim fracture and rotator cuff tear. The axillary nerve palsy was incomplete and recovering. Following improvement in manual muscle testing (MMT) of the deltoid from grade $4 / 5$ to $5 / 5$ and the disappearance of the sensory disturbance three months after injury, we performed an arthroscopic rotator cuff repair using a suture bridge technique (Figure 4). Shoulder function recovered satisfactorily with approximately full ranges of motion one year after surgery. Constant score recovered from 38 points to 75 points.

\section{Discussion}

Despite anterior dislocations of the shoulder commonly associated with glenoid rim fractures, rotator cuff tears, and axillary nerve palsy, there is no reported case presenting all four injuries of the shoulder concomitantly. The incidence of axillary nerve palsy following anterior dislocation of the shoulder is $9-10 \%[7,8]$. The mechanism of axillary nerve injury in shoulder dislocations consists of traction and compression forces applied during stretching of the nerve across the humerus as it dislocates anteriorly. Prognosis for neurological recovery is reportedly excellent, as lesions associated with dislocations are typically either neuropraxic 


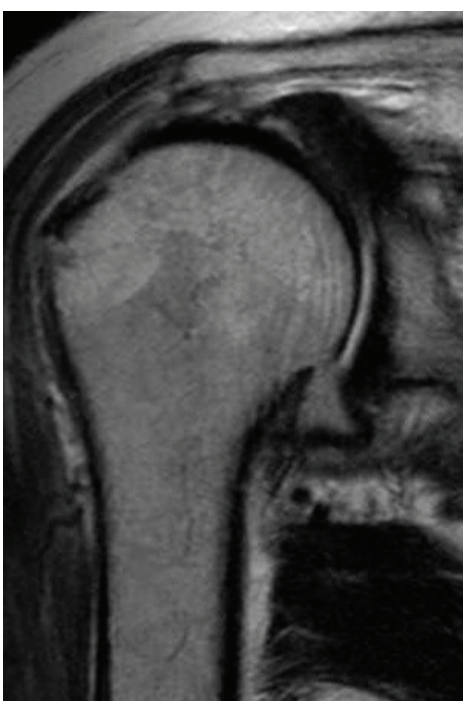

(a)

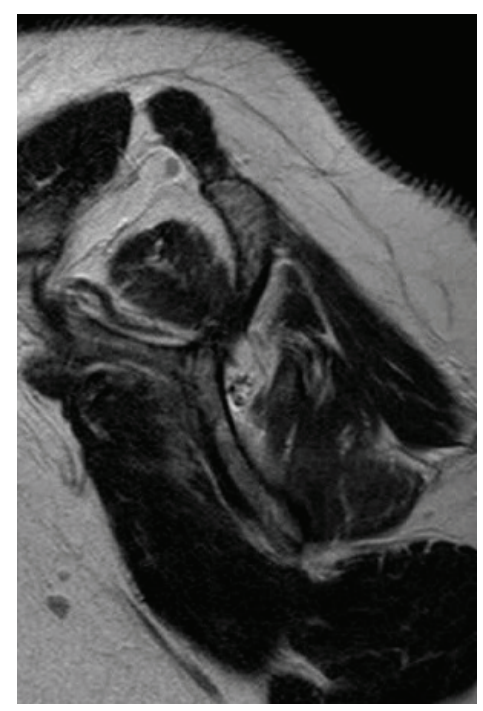

(b)

FIGURE 3: MRI imaging upon initial presentation to our hospital. (a) Coronal view of T2 shows a large tear approximately $3 \mathrm{~cm}$ long in the supraspinatus tendon. (b) Oblique sagittal view of T2 shows atrophy and fatty degeneration of the supraspinatus muscle.

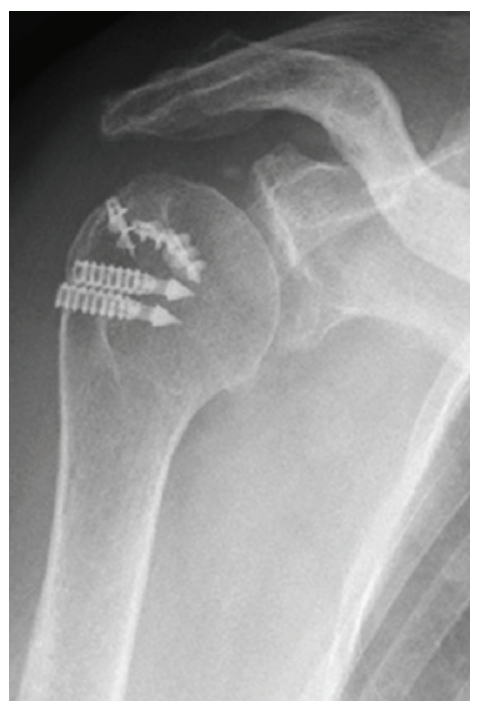

FIGURE 4: X-ray imaging after arthroscopic rotator cuff repair using a suture bridge technique.

or axonotmetic lesions which are classified as class1 or class 2 of Sunderland classification [9, 10]. Therefore, early diagnosis and surgical repair of rotator cuff tears associated with shoulder dislocation is crucial, as early repairs favor improved outcomes compared with delayed repairs $[3,11]$. Because of pain and swelling of the shoulder, it would be difficult to diagnose rotator cuff tears by physical remarks after dislocation of the shoulder. Since $14-63 \%$ of anterior dislocations are associated with rotator cuff tears [12], MRI should be performed when the patient has persistent pain or muscle weakness after reduction of the shoulder. Although Mall et al. reported that there was no indication that acute repair in traumatic injuries produced better outcomes [13], Simonich and Wright recommend proceeding with rotator cuff repair as soon as the diagnosis has been made in order to obtain the optimal results for terrible triad of injuries [14]. The tears of tendons of the rotator cuff cause atrophy and fatty degeneration of the rotator cuff muscles. These changes are irreversible and surgical repair is most effective for the prevention. The prognosis of unhappy triad depends essentially on brachial plexus recovery when the rotator cuff has been repaired early [15]. In this case, it is uncertain when the rotator cuff tear occurred. The prevalence of rotator cuff tear in the $60 \mathrm{~s}$ is $15.2 \%$ [16], and the incidence of rotator cuff tear with first-time anterior traumatic shoulder dislocation is $47.8 \%$ in the $60 \mathrm{~s}$ [17]. Although many elderly patients have symptomatic or asymptomatic rotator cuff tear, the prevalence rate of rotator cuff tear increases in association 
with dislocation of the shoulder. Moreover, she had not been suffering from shoulder symptoms before the injury. Therefore, the rotator cuff tear might be traumatic in this case.

A displacement threshold has been proposed for glenoid rim fractures, with a displacement of more than $4 \mathrm{~mm}$ of articular step-off, or more than $20 \%$ involvement of the glenoid, indicating that surgery is required [18]. In a cadaveric study, Itoi et al. reported that a defect with a width at least $21 \%$ of the glenoid length causes shoulder instability [19]. In the present case, the width of the bony fragment was 30\% of the glenoid length; therefore, surgery may be indicated for the glenoid rim fracture according to Itoi et al. In contrast, Maquieira et al. reported that traumatic anterior shoulder dislocations with a large, displaced glenoid rim fracture can be successfully treated nonsurgically [6]. We did not perform osteosynthesis in the present case, as the fracture had already achieved union upon referral to our hospital.

There has been no reported case of the "terrible tetrad," which consists of concurrent rotator cuff tear and axillary nerve palsy associated with anterior dislocation of the shoulder and a large glenoid rim fracture. This study presented a case of the "terrible tetrad" of the shoulder for the first time. We conclude that surgeons should consider an operation to repair the rotator cuff, in an attempt to prevent rotator cuff degeneration, if the symptoms of the shoulder such as pain or limited motion last after reduction of the dislocation and the nerve recovery is predicted.

\section{Consent}

The patient provided consent for publication of this report and the accompanying image.

\section{Conflict of Interests}

There is no conflict of interests regarding the publication of this paper.

\section{References}

[1] D. Gonzalez and R. Lopez, "Concurrent rotator-cuff tear and brachial plexus palsy associated with anterior dislocation of the shoulder: a report of two cases," The Journal of Bone and Joint Surgery A, vol. 73, no. 4, pp. 620-621, 1991.

[2] O. Güven, Z. Akbar, S. Yalçin, and H. Gündeş, "Concomitant rotator cuff tear and brachial plexus injury in association with anterior shoulder dislocation: unhappy triad of the shoulder," Journal of Orthopaedic Trauma, vol. 8, no. 5, pp. 429-430, 1994.

[3] G. I. Groh and C. A. Rockwood Jr., “The terrible triad: anterior dislocation of the shoulder associated with rupture of the rotator cuff and injury to the brachial plexus," Journal of Shoulder and Elbow Surgery, vol. 4, no. 1, pp. 51-53, 1995.

[4] M. W. Payne, T. J. Doherty, K. A. Sequeira, and T. A. Miller, "Peripheral nerve injury associated with shoulder trauma: a retrospective study and review of the literature," Journal of Clinical Neuromuscular Disease, vol. 4, no. 1, pp. 1-6, 2002.

[5] R. Ideberg, S. Grevsten, and S. Larsson, "Epidemiology of scapular fractures. Incidence and classification of 338 fractures,"
Acta Orthopaedica Scandinavica, vol. 66, no. 5, pp. 395-397, 1995.

[6] G. J. Maquieira, N. Espinosa, C. Gerber, and K. Eid, "Nonoperative treatment of large anterior glenoid rim fractures after traumatic anterior dislocation of the shoulder," The Journal of Bone and Joint Surgery B, vol. 89, no. 10, pp. 1347-1351, 2007.

[7] R. J. Neviaser, T. J. Neviaser, and J. S. Neviaser, "Concurrent rupture of the rotator cuff and anterior dislocation of the shoulder in the older patient," The Journal of Bone and Joint Surgery A, vol. 70, no. 9, pp. 1308-1311, 1988.

[8] C. M. Robinson, N. Shur, T. Sharpe, A. Ray, and I. R. Murray, "Injuries associated with traumatic anterior glenohumeral dislocations," The Journal of Bone and Joint Surgery A, vol. 94, no. 1, pp. 18-26, 2012.

[9] N. Apaydin, R. S. Tubbs, M. Loukas, and F. Duparc, "Review of the surgical anatomy of the axillary nerve and the anatomic basis of its iatrogenic and traumatic injury," Surgical and Radiologic Anatomy, vol. 32, no. 3, pp. 193-201, 2010.

[10] S. Sunderland, "A classification of peripheral nerve injuries producing loss of function," Brain, vol. 74, no. 4, pp. 491-516, 1951.

[11] R. W. Bassett and R. H. Cofield, "Acute tears of the rotator cuff. The timing of surgical repair," Clinical Orthopaedics and Related Research, vol. 175, pp. 18-24, 1983.

[12] S. Cutts, M. Prempeh, and S. Drew, "Anterior shoulder dislocation," Annals of the Royal College of Surgeons of England, vol. 91, no. 1, pp. 2-7, 2009.

[13] N. A. Mall, A. S. Lee, J. Chahal et al., "An evidenced-based examination of the epidemiology and outcomes of traumatic rotator cuff tears," Arthroscopy, vol. 29, no. 2, pp. 366-376, 2013.

[14] S. D. Simonich and T. W. Wright, "Terrible triad of the shoulder," Journal of Shoulder and Elbow Surgery, vol. 12, no. 6, pp. 566568, 2003.

[15] J.-N. Goubier, L.-D. Duranthon, E. Vandenbussche, R. Kakkar, and B. Augereau, "Anterior dislocation of the shoulder with rotator cuff injury and brachial plexus palsy: a case report," Journal of Shoulder and Elbow Surgery, vol. 13, no. 3, pp. 362$363,2004$.

[16] H. Minagawa, N. Yamamoto, H. Abe et al., "Prevalence of symptomatic and asymptomatic rotator cuff tears in the general population: from mass-screening in one village," Journal of Orthopaedics, vol. 10, no. 1, pp. 8-12, 2013.

[17] R. Berbig, D. Weishaupt, J. Prim, and O. Shahin, "Primary anterior shoulder dislocation and rotator cuff tears," Journal of Shoulder and Elbow Surgery, vol. 8, no. 3, pp. 220-225, 1999.

[18] P. A. Cole, G. Freeman, and J. R. Dubin, "Scapula fractures," Current Reviews in Musculoskeletal Medicine, vol. 6, no. 1, pp. 79-87, 2013.

[19] E. Itoi, S.-B. Lee, L. J. Berglund, L. L. Berge, and K.-N. An, "The effect of a glenoid defect on anteroinferior stability of the shoulder after Bankart repair: a cadaveric study," The Journal of Bone and Joint Surgery A, vol. 82, no. 1, pp. 35-46, 2000. 


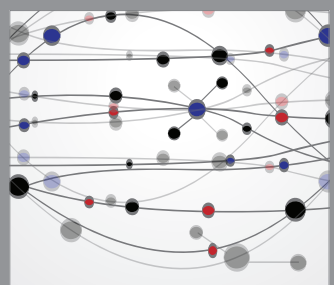

The Scientific World Journal
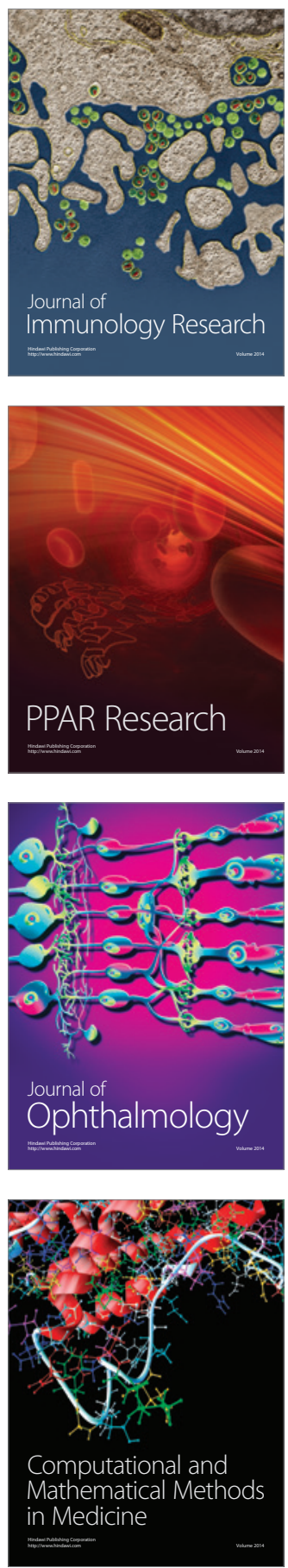

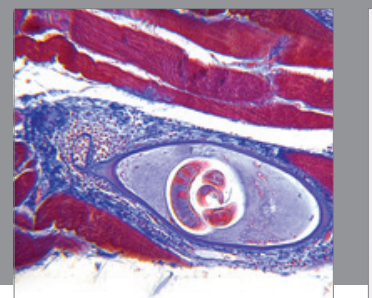

Gastroenterology

Research and Practice
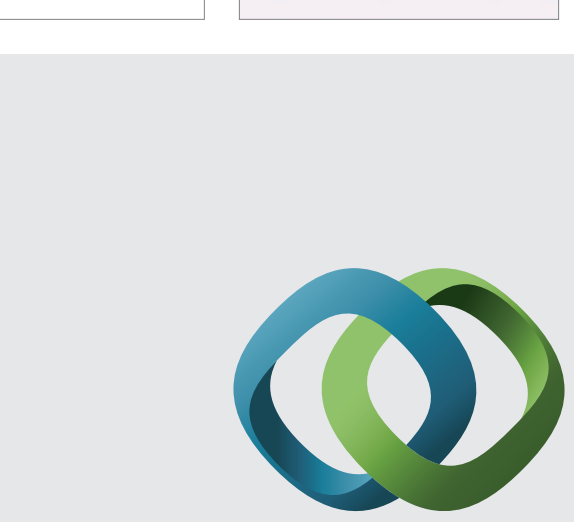

\section{Hindawi}

Submit your manuscripts at

http://www.hindawi.com
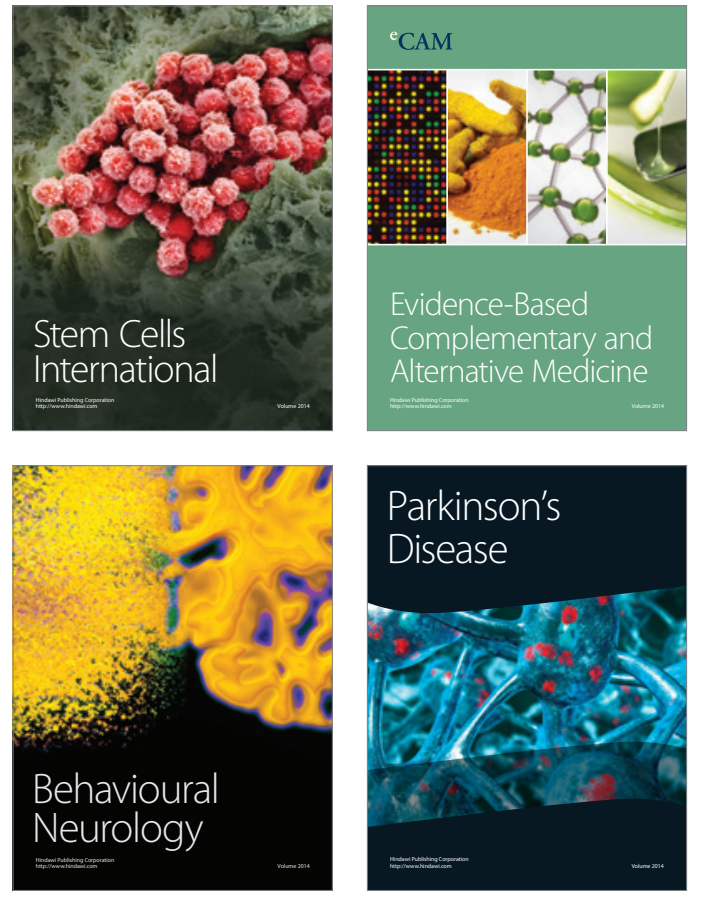
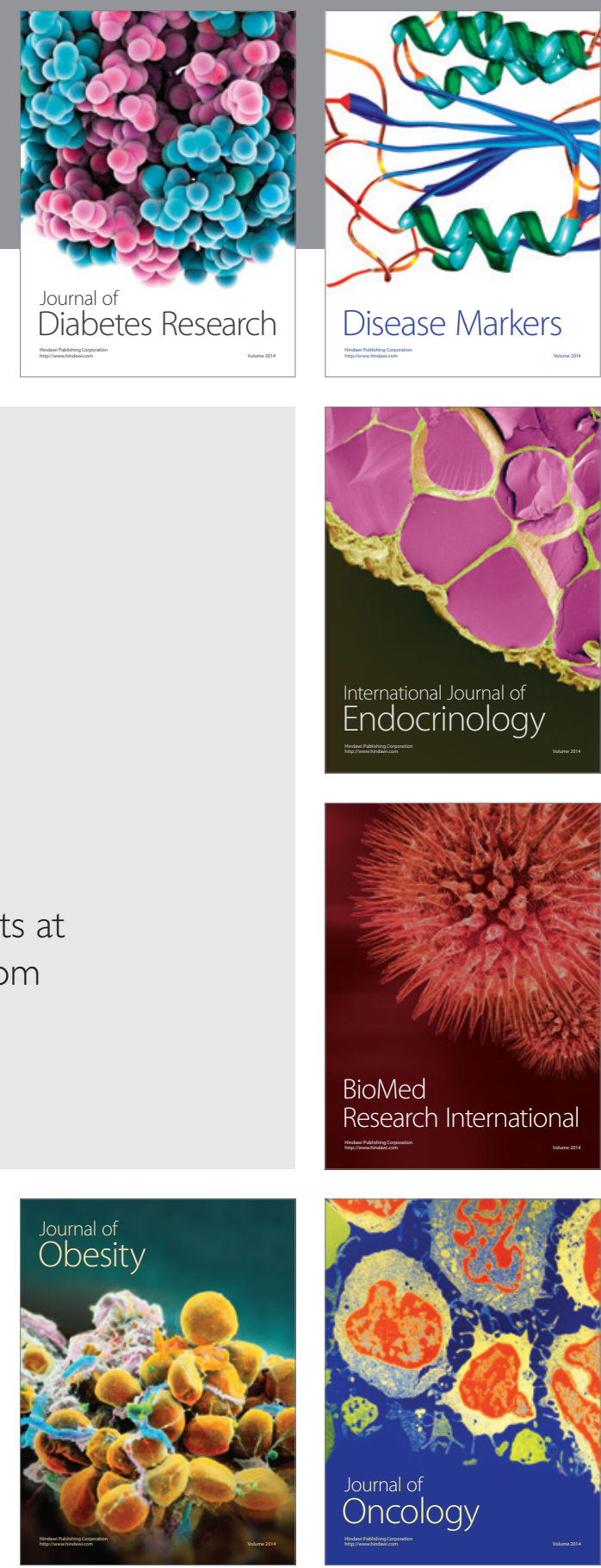

Disease Markers
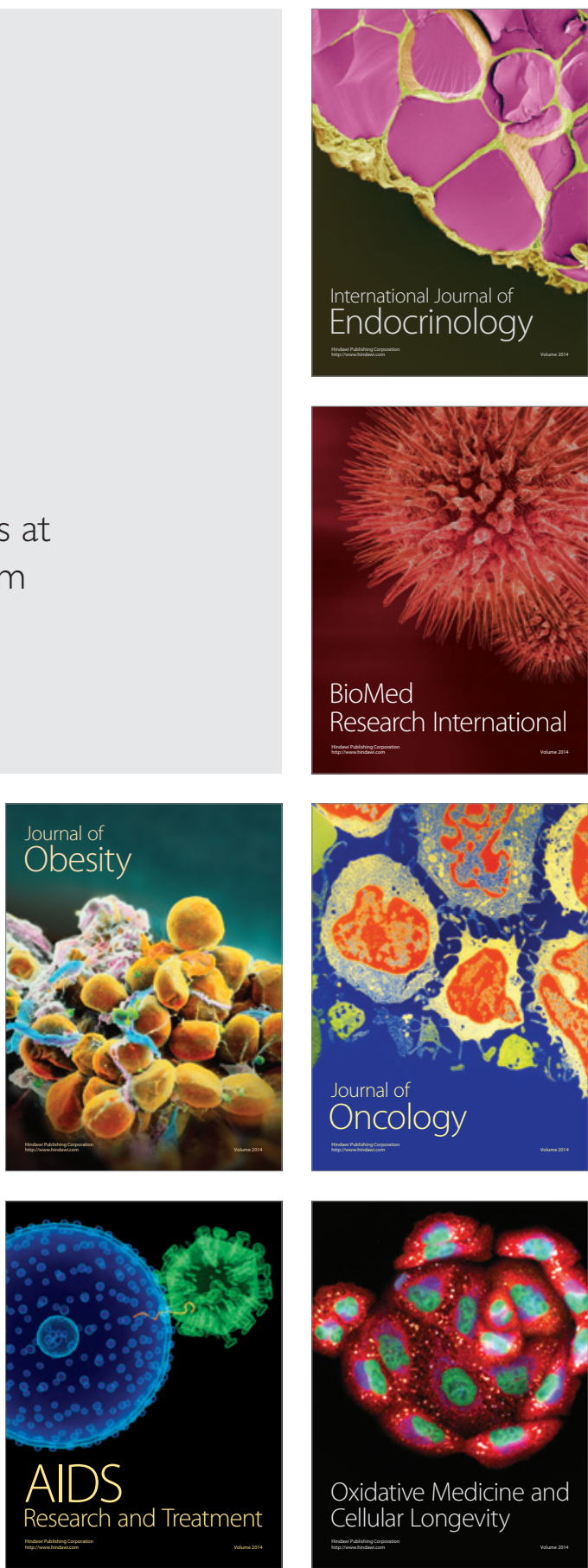